\title{
Enhancing Pre-service Science Teachers' Understanding and Practices of SocioScientific Issues (SSIs)-Based Teaching via an Online Mentoring Program
}

\author{
Sasithep Pitiporntapin ${ }^{1}$, Naruemon Yutakom ${ }^{1}$, Troy D. Sadler ${ }^{2} \&$ Lisa Hines $^{3}$ \\ ${ }^{1}$ Division of Science Education, Department of Education, Faculty of Education, Kasetsart University, Bangkok, \\ Thailand \\ ${ }^{2}$ ReSTEM Institute: Reimagining \& Researching STEM Education, The University of Missouri, Columbia, USA \\ ${ }^{3}$ Department of Biology, University of Colorado at Colorado Springs, USA \\ Correspondence: Sasithep Pitiporntapin. Tel: 66-(0)-2579-7114 ext.161. E-mail: fedustp@ku.ac.th
}

Received: February 19, $2018 \quad$ Accepted: March 10, $2018 \quad$ Online Published: April 19, 2018

doi:10.5539/ass.v14n5p1

URL: https://doi.org/10.5539/ass.v14n5p1

\begin{abstract}
Science education reformists in Thailand promote the use of socioscientific issues (SSIs)-based teaching to enrich scientific literacy for global citizenship. To achieve this goal, Thai pre-service science teachers (PSTs) must know how to effectively integrate SSIs into their science teaching practices. The purpose of this study was to enhance PSTs' understanding and practices of SSIs-based teaching via the online mentoring (OM) program. Three PSTs were selected as case studies, and data were collected from online observations, semi-structured interviews, online discussions, and online document reviews. The analytical methods included within-case and cross-case analysis. This study found that the OM program was effective in enhancing PSTs' understanding and practices of SSIs-based teaching. As a result, their teaching practices evolved from conveying content knowledge to promoting higher-order cognitive practices. In addition, the PSTs demonstrated a deeper appreciation for OM programs as a means to enhance teaching practices. This research demonstrates how the implementation of OM programs has the potential to be powerful tool for professional development of science educators, which is essential for transforming science educational practices.
\end{abstract}

Keywords: pre-service science teacher, SocioScientific Issues (SSIs)-based Teaching, online mentoring

\section{Introduction}

Scientific knowledge and $21^{\text {st }}$ century learning are evolving, parallel with societal needs. Teaching is viewed as a microcosm of society that relates to reasoning with respect to socioscientific issues (SSIs). SSIs form a link between relevant social issues and science and, as a result, have become important topics in science education (Kolsto, 2001). The discussion of SSIs in the classroom is not only useful in terms of student' learning about content, processes and the nature of science and technology, but also in terms of students' cognitive, social, political, moral and ethical development (Sadler, 2004). Therefore, it is important that science educators provide students with experiences that are relevant to their present and future social experiences.

SSIs-based instruction is considered a powerful strategy for supporting science learning and the development of scientific literacy (Presley et al., 2013). However, there are many reports that point out the difficulties in this teaching approach. For example, some teachers are concerned about many issues, which include finding relevant instructional materials, time limitations (Lee, Abd-ElKhalick, \& Choi, 2006), multiple ethical identities including cultural, ethnic, religious and gender perspectives, lack of administrative support, and lack of confidence in their ability to discuss SSIs (Saunders \& Renni, 2011). In Thailand, Nuangchalerm (2009) recognized the need to prepare science teachers who can face science and social issues, as well as respond to student questions regarding SSIs, in order to meet the goals set forth in science education. To cultivate science teachers, pre-service science teachers (PSTs) represent a particularly important population in terms of educational reform. PSTs must have a good understanding with respect to new classroom practices (Bell, 1998).

Consistent interaction with university mentors can improve PSTs' pedagogy content knowledge with respect to knowledge of students' learning difficulties and specific practical teaching strategies (van Driel et al., 2002). In 
addition, Perry and Power (2004) indicate that PSTs can develop their practical knowledge through experience and reflection facilitated by mentors. While Beck and Kosnik (2002) pointed out that the separation and lack of time with PSTs can result in conflicts between PSTs and the university supervisors. Furthermore, Pena and Almaguer (2007) found that PSTs need more time to discuss ideas with mentors in order to have a positive impact on their teaching practices. However, consistent interaction is not always feasible due to time constraints and location.

One way to overcome these barriers is to integrate technology into professional development as a means to facilitate communication and provide support to PSTs. Instead of trying to accommodate busy work schedules, PSTs and mentors can interact more frequently and conveniently online (Ensher et al., 2003). Online mentoring $(\mathrm{OM})$ is a recent development in the field of mentoring that has the potential to be more advantageous than traditional forms (Hunt, 2005). It provides academic support to online learners while ensuring the mentoring location is functional and conducive to a positive learning environment. In order to be a beneficial program, the mentor must have excellent listening and conversational skills, be able to answer general questions, and ensure the mentees are engaged in activities that promote their academic progress. The mentor may also assist the learner with online courses (Michigan Virtual University, 2014). Teachers who previously participated in an OM program reported that they were able to obtain suggestions for their lesson plans and solutions to teaching dilemmas (Miller, 1999). In addition, online mentors integrated into distance programs have shown to be effective and have had a positive impact to some university programs (Gewin, 2005).

In order to address the aforementioned problems, a novel OM program was developed to enhance PSTs' understanding and practices of SSIs-based teaching. The use of this SSIs-based teaching was considered a means of changing their understandings and practices to be in line with educational reform.

\section{Research Questions}

The research questions in this study are: (1) What changes in the PSTs' understanding and practices of SSIs-based teaching occurred as a result of the OM program?, and (2)Were the PSTs' satisfied with the OM program?

\section{Theoretical Framework}

In a classroom setting, students are considered a miniature society who addresses the conflicts regarding SSIs. Through these issues, many individuals will improve their scientific literacy (Presley et al., 2013) by taking real-life situations that are scientific in nature, but are influenced by other factors, such as social, political, and ethical issues (Roberts, 2007). To be successful using SSIs in the classroom, teachers should provide ways for students to engage in higher-order cognitive practices, such as argumentation, reasoning, and decision-making (Presley et al., 2013). With respect to teaching aids and materials for SSI-based teaching, teachers can use recent news media, such as articles from newspapers or television reports, to make a connection between what students are learning in class and current world events (Klosterman, Sadler, \& Brown, 2012). In addition, technology can be used in a variety of ways to enhance SSIs-based teaching and has the potential to be a powerful tool for providing access to relevant social issues (Evagorou, 2011). Students can access SSI media resources with technology (Presley et al., 2013). However, there are few research reports about SSIs-based teaching among PSTs in Thailand (Nuangchalerm, 2009; Nuangchalerm \& Kwuanthong, 2010; Wongsri \& Nuangchalerm, 2010).

A PST is considered as an adult learner within the teaching community. The members in this community are expected to be lifelong learners. They also actively construct knowledge (Northfield, 1998), which is an element of teacher empowerment for pursuing their craft with enthusiasm, confidence, and authority (Lichtenstein et al., 1992). Elbaz (1981) stated that a teachers' knowledge is "dynamic" and "is held in active relation to practice and used to give shape to that practice". However, learning to teach is a complex process and PSTs encounter various problems or difficulties during the process (Zembal-Saul, Blumenfeld, \& Krajcik, 2000). Therefore, they are also required to have active involvement with more knowledgeable persons, such as university supervisors and cooperating teachers. These people can be viewed as facilitators who support their learning (Bell, 1993). However, they seem to have limited time within a school day for mentoring because of non-instructional duties or because they need to provide additional guidance to some students (Feiman-Nemser, 2012). To address this issue, online mentoring poses a more viable option for professional development.

Online mentoring provides is a convenient way for a learner to reach a mentor without time constraints (Wah, 2000), at minimal cost, flexibility (Perren, 2003), and with less prejudice (Shpigelman, Weiss, \& Reiter, 2009). Bang and Luft (2014) suggest that online mentoring programs are an effective tool for the transfer of knowledge from experts to novices, and thus, expediting the professional induction and growth of new science teachers. The teachers who participate in online mentoring programs can benefit from suggestions for their lesson plans and 
solutions to teaching dilemmas (Miller, 1999).

\section{Research Methodology}

For this study, a qualitative research procedure based on an interpretive paradigm was implemented. A case study approach was conducted to assess the impact of the OM Program on PSTs' understanding and practices of SSIs-based teaching. Three case studies were selected for identifying the changes in their knowledge and practices of SSIs-based teaching occurred as a result of the OM program as well as their satisfaction with the OM program. A major strength of the case study design is the ability to deduce cause and effect (Cohen, Manion, \& Morrison, 2000).

\subsection{Context of the Study}

This research was conducted within the Division of Science Education, Department of Education at a University in Thailand. The participants were PSTs who were preparing to be primary science educators at the primary or secondary level. In this program, graduates are expected to have strong content knowledge, extensive pedagogical skills for effective science teaching, and a professional code of conduct and ethics.

The PSTs have to enroll in a series of professional development courses that are related to professional experience standards required by the Teachers Council of Thailand, such as field experiences related to observation, practice and research. In these courses, the PSTs will visit a partnering school to gain a better understanding of school culture, classroom culture, teaching and learning, classroom management, supervision, student discipline, school counseling, management, student affairs, extracurricular activities, and quality assurance systems.

Before participating in the field experience, the PSTs need to attend an orientation program to help prepare them. In addition, PSTs observe classroom teaching and learning one week prior to their teaching practice. While in practice, cooperating teachers and university supervisors track their progress, and suggest strengths and weaknesses of their teaching. Typically, these courses require five days a week at a local school, with 8-12 hours of practice teaching. During their practicum, they have to participate in four teaching conferences, which include orientation, two in-service conferences, and a post-service conference. These conferences are intended to promote reflective thinking about their understanding and teaching practices, as well as the problems that they found in classroom.

For this study, the case studies were asked to participate in the OM program during their teaching practicum. The OM program was designed to provide a platform for PSTs to enhance their understanding and practices of SSIs-based teaching. They could access this program via "www.clinicssi.edu.ac.th", a secure website. The attributes of this program include: (1) teaching objectives that focus on promoting SSIs-based teaching, (2) pedagogical approaches that allow for higher-order practices, such as argumentation, reasoning and explanation, (3) practical examples of SSIs-based teaching, (4) opportunity to consult with an expert, (5) a means to share ideas with other PSTs, (6) the opportunity for reflection on practices, (7) the ability to participate in meaningful exchanges, (8) a friendly environment and peer support, and (9) clear communication channels. Importantly, the OM program is easily accessible and can be done at their convenience. This program presented content in Thai language and was free of charge to the participants. It also provides a virtual room called "ClinicSSI", where there are various activities designed to promote active participation, such as reading information, watching a video clip, reflecting on practices via an online journal, a discussion board, as well as classroom observation and chatting with an expert via Google hangout.

\subsection{Research Participants}

The research participants were 3 out of 37 PSTs in the fifth year of a B.Ed. (Teaching Science) program during the 2016 academic year. For case studies, the selection of a case is critical for understanding holistic views or processes in particular instances. Purposive sampling should be used for choosing cases to study in order to gain rich information (Merriam, 1998). It also provides a prototype and yields in-depth understanding, rather than generalization from the sample to a larger population (Patton, 2002). The researcher asked for volunteers to participate in a research study to evaluate the efficacy of a newly developed OM program. The PSTs were selected to be case studies based on three criteria: (1) they expressed interest in being research participants, (2) they had an interest in learning more about SSIs-based teaching, and (3) they were willing to commit to all activities in the OM program. "Wandee", "Somsri", and "Ratree", the participants' pseudonyms, were selected to be case studies for conducting an in-depth qualitative assessment regarding the efficacy of the OM program on enhancing understanding and practices of SSIs-based teaching, and to assess overall satisfaction with the OM program. 


\section{Case of Wandee}

At the time of study, Wandee taught science for $8^{\text {th }}$ grade students in a large, girls' school located in Nonthaburi province. She taught 9 periods per week. In her classroom, there were 47 students who came from middle class families. The learning achievement in science was at the moderate level. Typically, Wandee asked students to work in groups of 4-5 people. Her students typically answered her questions based on their beliefs rather than scientific reasoning. When she used questioning to guide students, they would often keep quiet. During group work, outstanding students always did the experiments, while the other students would wait to copy from their peers. She intended to use SSIs to teach students about the structures and functions of sexual organs as a means to promote her students' scientific reasoning skills. She allotted 100 minutes ( 2 periods) for teaching this concept and used the laboratory classroom facility.

\section{Case Somsri}

In the 2016 academic year, Somsri taught science for grade $4^{\text {th }}$ students in a medium-sized public school under the Bangkok Metropolitan Administration. There were 24 students in her class, which comprised 12 boys and 12girls. Most of her students came from low socioeconomic level families, and most parents were workers near the school area. However, most of her students in this class had family problems. Their parents were not deeply concerned about their children's education, and most of these students had low achievement scores. Therefore, she was interested in promoting student interest in learning. The relationship between Somsri and her students was based on trust and respect. She intended to use SSIs-based teaching in her class to promote the discussion of science concepts in relation to daily life and society. She intended to discuss the construction of waste power plant as part of unit on light energy for 1 period (60 minutes). For her classroom setting, Somsri taught her students in laboratory classroom facility.

\section{Case Ratree}

Ratree taught science to $3^{\text {rd }}$ grade students in a large public school under the Bangkok Metropolitan Administration. There were 37 students in her class, which composed of 14 boys and 23 girls. Similar with Somsri, most of her students lived in Bangkok and came from low socioeconomic level families. Some students were orphans under the control of a child centre that supported their tuition fees. The average achievement scores in science were quite low. Most of her students did not pay attention in her lesson. They could not answer her questions. Ratree believed that many of her students perceived that science was irrelevant to their daily life. She intended to use SSIs-based teaching in her classroom to promote the practice of higher-order thinking related to science. In her SSI-based lesson, she addressed the topic of the problem of using natural resources and the guideline for conservation for 1 period $(60$ minutes). Ratree used the laboratory room because her responsibilities included the supervision of the laboratory space.

\subsection{Data Collection and Analysis}

PSTs who had field experiences in the first semester of 2016 academic year were asked to volunteer as a case study. The OM program provided a means to discuss with the researcher and reflect about their understanding and practices of SSIs-based teaching. The researcher collected data from online observations, semi-structured interviews, video conferencing, online chatting, and review of their teaching documents (e.g. course outlines, lesson plans, worksheets, and action research reports, etc.). The researcher also used semi-structure interviews, approximately 20 to 30 minutes and informal interviews for clarification and facilitating analysis, validity checks, and triangulation. Each data source should be combined with different data sources in order to enhance validity and to cross-check the findings via triangulation (Patton, 2002). At the end of OM program, all cases in this program received an e-certificate of participation from the researcher.

During implementation of the OM program, data collected from PSTs, cooperative teachers and university supervisors were analyzed to understand PSTs' use of SSIs in their classrooms, their difficulties in using SSIs, and their needs for professional development in SSIs-based teaching. Quantitative data analysis involved the use of descriptive statistics to identify the more frequent responses. For qualitative data analysis, the questionnaire responses were analyzed using content analysis. The interviews were transcribed verbatim. Then, the researcher read all data to seek relationship patterns. After that, the data were open-coded to identify patterns and emerging themes that were relevant to the research question.

All collected data from three case studies were analyzed using within-case and cross-case analyses in order to reflect the PSTs' change of understanding and practices of SSIs-based teaching both before and during participation in the OM program, as well as their satisfaction with the OM program. The within-case analysis was conducted by using the constant comparative method. The process of data analysis from using constant 
comparative method was composed of four steps: comparing incidents applicable to each category; integrating categories and their properties; delimiting the theory; and reducing and refining categories and their properties (Lincoln \& Guba, 1985).

\section{Findings}

This report illustrates the experiences and perceptions of three PSTs' regarding SSIs-based teaching prior to and during participation in a newly developed OM program. The strengths and limitations of the OM program for promoting PSTs' understanding and practices of SSIs-based teaching were evaluated. The findings across them were categorized into themes from a cross-case analysis. The themes for these changes are presented below.

\subsection{The Changes in PSTs' Understanding of SSIs-Based Teaching}

\subsubsection{They Could Classify Which Issues Are SSIs}

The findings from the three cases revealed that, before participating in the OM program, they were unclear on the definition of SSIs. They could not identify which issues were SSIs because they did not know the characteristics that distinguished SSIs from scientific or social issues. For example, Wandee thought that SSIs were hot issues related to science and society, as she stated, "I considered SSIs as issues that involved science and technology. For example, I used to bring up the issue about stomach reduction for losing weight, and I thought that this issue is SSI because it related to science and society" (The group meeting, October 21, 2016). Similarly, Somsri thought that all science news is SSIs, as she stated, "I selected only the pictures that related to science in the newspapers to make my decision" (Interview, October 30, 2016). These two cases showed that they were unaware of the controversial and ethical aspect of SSIs. Ratree was able to correctly identify SSIs based on what she had learned from her coursework. She revealed that: I used to study about SSIs in the "Science and Technology Education and Society" course. My teacher gave me examples of SSIs, and I still remembered which issues were SSIs. But in depth, I cannot remember the criteria to identify whether or not the provided issues are SSIs. (The group meeting, October 21, 2016)

While participating in the OM program, they gradually developed a better understanding on the definition of SSIs, as reflected by their post-test responses. They were able to identify which of the presented issues were SSIs, and their rationale was correct. For example, Wandee revealed her understanding of the definition of SSIs in her journal entry: Now, I can identify which issues are SSIs. Previously, I understood that SSIs are issues related to science and society, but in fact, there are four aspects to consider. First, it is a controversial issue, which emerges from the difference in opinions. Second, it relates to accurate scientific concepts and processes. There are dimensions of morals, ethics, politics, economy, and religion. SSIs are also ill-structured, complex, have an unclear conclusion, and reflect a continuing problem situation. (Journal entry of the first lesson, December 17, 2016)

\subsubsection{They Recognized the Importance of SSIs-Based Teaching}

Initially, Wandee had the impression that the importance of SSIs-based teaching is the transmission of content knowledge, as she stated "I understand that the main aim for SSIs-based teaching is for students to learn knowledge that scientists discovered. It is difficult for people who are in other fields of studies" (Pretest of second lesson, October 21, 2016). In the case of Somsri, she mentioned enhancing students' critical thinking about news in their daily life, as reflected in pretest, "In the current news, there is much propaganda presented regarding society, which is dangerous to students. Therefore, science teaching should promote students' critical thinking about news in their daily life" (Pretest of the second lesson, November 3, 2016). However, Ratree thought that her students were too young to know about SSIs, as she stated, "My students are too young. They are in grade 3 and do not know much about what happens in society" (The group meeting, October 21, 2016).

As the OM program progressed, they could identify important aspects of SSIs-based teaching by reading about the history of this science teaching approach. Wandee referred to the application of student knowledge in SSIs-based teaching, as she reflected, "For success in SSIs-based teaching, students should apply knowledge to daily life" (Posttest, November 12, 2016). Both Somsri and Ratree could compare the characteristics of SSIs-based teaching and the traditional teaching approach. For example, Somsri stated in her journal entry: I can identify the different characteristics of SSIs-based teaching and the traditional teaching approach more so than before. This approach relates to various social dimensions. Teacher can learn with students on content related to SSIs. But in the traditional approach, teachers provide knowledge directly to students. Students do not have much chance to share their opinions. (Journal entry of the third lesson, December 14, 2016)

\subsubsection{They Could Identify the Characteristics of SSIs-Based Teaching}

Before participating in the OM program, these three cases did not know the main characteristics of SSIs-base 
teaching, especially the link to ethics and morals. They understood that a teacher uses SSIs from the news or internet in the classroom as a way to promote students' interest. As shown in case of Wandee, she stated, "As far as I know, teachers use SSIs to motivate student interest in a science lesson. I think that teaching science is for making students smarter in science" (Pretest, November 8, 2016). Similarly, Somsri believed that teachers use SSIs for promoting students' interest in a lesson, similar to a general teaching approach, as she stated "To my understanding, the characteristics of SSIs-based teaching are not much different from other teaching approaches, but it is focused on bringing SSIs into the classroom as means to promote student interest" (Pretest of the third lesson, November 9, 2016). For Ratree, she stated, "The characteristic of SSIs-based teaching according to my understanding is about using news about SSIs in classroom for students' to debate" (Pretest of the third lesson, November 11, 2016).

Through the OM program, they had acquired more knowledge on how to use this teaching approach in classroom. They understood the characteristics of SSIs, ways to use SSIs to drive a lesson, the role of teacher and the role of students. This improved understanding had a positive impact on their teaching practices.

5.1.4 They Learned Alternative Methods and Models for SSIs-Based Teaching Rather Than Discussion and General Steps of teaching in Classroom

Initially, all case studies accepted that they did not know much about the teaching models for SSIs-based teaching. In case of Wandee and Somsri, they were only aware of discussion as the main teaching method for SSIs-based teaching, where students have chance to share their ideas and provide reasons in classroom. In the case of Ratree, she identified debate as the main method for this teaching approach. Additionally, Somsri and Wandee thought that there were three steps of SSIs-based teaching, similar to a general teaching model, which is composed of an introduction, learning activities, and a conclusion.

After the fourth lesson of the OM program, all of them were able to identify various methods and models for SSIs-based teaching, such as scientific argumentation, reasoning, debating, discussion, role-playing, and presentations. Moreover, they also expressed that they had a better understanding of these teaching models compared to what they had learned from their coursework. For example, Ratree had a better understanding about the characteristics of SSIs-based teaching. As she stated: I knew that SSIs-based teaching relates to real context or situations. It also focuses on higher-order practices. Teachers do not have to use only debating in their classrooms, but they can use various methods to promote students' reflections and sharing of opinions about SSIs. Students can search data, do experiments, analyze data, and make conclusions. Moreover, they interact with each other and understand the link of SSIs to various social dimensions and ethical and moral issues. (Posttest of the third lesson, November 11, 2016)

5.1.5 They Improved Their Understanding of the Various Dimensions of Learning Assessment for SSIs-Based Teaching

Before participating in the OM program, Somsri and Ratree identified that assessing students' learning from SSIs-based teaching is not different from other teaching approaches, which includes the cognitive domain, the psychomotor domain, and the affective domain. Ratree stated, "Teachers can assess student learning with SSIs-based teaching from considering their tasks. Typically, it is not different from any other teaching approach" (Pretest of the fifth lesson, November 29, 2016). However, Wandee perceived that it would be difficult to assess her students with SSIs-based teaching because this teaching approach is new for her, as she reflected, "I thought that it is difficult for assessing students' learning from SSIs-based teaching because I have never observed it in a typical classroom. Furthermore, it must relate to the learning assessment guideline provided in Thai core curriculum B.E. 2551" (The group meeting, October 21, 2016).

As the OM program progressed, their understanding of learning assessment evolved. Wandee and Ratree increased their understanding about learning assessment for SSIs-based teaching with respect to assessing students' higher-order practices. For example, Wandee stated, "For learning assessment for SSIs-based teaching, teachers should consider the consistency between learning objectives and learning assessment. Teachers should not only focus on assessing students' cognitive domain, but also on higher-order practices and attitude, ethics or morals"(Interview, December 28, 2016). Somsri learned more about methods of assessing students' learning from SSIs-based teaching, such as observing students' sharing of opinions, reviewing students' learning journals, and performance on tasks. As she stated, "Assessment for this teaching approach is concerned with many aspects. Teachers can use various methods to assess their students, such as observing students' sharing of opinions, individually or in a group, or reviewing students' learning journals and tasks" (Posttest of the fifth lesson, December 24, 2016). 


\subsection{The Changes in PSTs' Practices of SSIs-Based Teaching}

5.2.1 They Provided More Opportunity for Students to Share Ideas, Rather Than Discuss Content Knowledge, in the Classroom

Before participating in the OM program, Wandee, Somsri and Ratree accepted that most of their students rarely shared ideas in classroom. To cope with this problem, they tried to use questions to motivate students' sharing of ideas. For example, Wandee gave extra points to the ones who participated more in her class. However, she always found that her students' answers used intuition in their reasoning as shown in the dialogue in the separation of water from electricity lesson below:

Wandee: Why do you think that it is different in the two test tubes?

Students: Because it is in different test tubes.

Wandee: That does not mean the two test tubes will have different gases. From doing the experiment, why do you think that it is different?

Students: I do not know.

(Initial classroom observation from September 7, 2016)

After completing the OM program, all cases incorporated current SSIs for launching a lesson in their class. As a result, Wandee's students were more interested in her lesson and asked more questions in the class. In addition, students who sat in the back put more effort in trying to answer her questions. But in case of Somsri and Ratree, their students were younger than Wandee's students. They still kept quiet. To address this problem, Somsri used probing questions and writing frameworks for them to share ideas as shown in her journal entry: I found that most of my students seemed too shy to share ideas. For the ones who shared ideas, they did not provide any evidence to support their ideas, so I have to guide them with easy questions and explain in more detail what I want them to discuss. (Journal entry after teaching, December14, 2016)

Similarly, Ratree asked her students to write down their ideas on a small piece of paper before discussion. As the results of their practices, their students had more participation in sharing ideas in classroom. As she reflected: $M y$ grade 3 students do not know about debating. I had to find new methods for promoting students to share ideas. Finally, I found that having them write down their ideas on a small piece of paper was a good way for my students to share their own ideas, and use the information to make a decision. (Journal entry in the third part of the OM program, December 15, 2016).

5.2.2 They Provided the Opportunity for Students to Link Their Scientific Knowledge to Various Social Dimensions

The findings from the three cases revealed that, before participating in the OM program, they seldom asked students to link what they learned to various social dimensions, such as politics, law, religion, or economics. Wandee and Ratree admitted that they were unable to design a lesson that incorporated social dimensions because they felt that a lot of the content was not concerned with society. For example, Wandee stated, "I have never designed a lesson to link it with any social dimensions because I was not aware of how relevant it is to my students. For me, I thought that it is difficult to link scientific content with social dimensions" (The group meeting, October 21, 2016). However, Somsri, always used the elaboration step of the 5E learning cycle to ask students to apply knowledge to their daily lives, as she stated, "I normally ask my students questions about application of knowledge to daily life in the elaboration stage, rather than linking the content to social dimensions. Honestly, I think that linking to social dimension is too difficult for my students at this age" (The group meeting, October 21, 2016). For all three cases, their practices before participating in the OM programs did not reflect the ability to use SSIs as a useful context for students to learn about specific science content knowledge, or make appropriate connections of the content to other areas of science or to other disciplines.

However, during participation in the OM program, they gradually developed their practices to incorporate social dimensions. Wandee and Somsri prepared guided questions to link their teaching content to politics, law, religion, and economics. Consequently, they revealed that their students had a better understanding of the material, with respect to applications in science, as well as other disciplines. Similarly, Ratree asked questions about the risks and benefits of SSIs as show in dialogue below.

Ratree: Please tell your friends about the benefits of dam construction that you found from your research.

Student: It will save water for agriculture during the dry season.

Ratree: How about the risks of dam construction? 
Student: Cutting down the forest

Ratree: When we have to make decisions about the construction of a dam, we have to consider both risks and benefits. From an economical standpoint, we have to think about whether it is worth the investment of construction.

(Online classroom observation from December 15, 2016)

In addition, they used media from the internet to link their lesson with social dimensions. For example, Wandee planned her lesson so that students would have to search for information themselves to support their own ideas, as described in her lesson plan: Students search information from provided learning resources, such as textbooks, knowledge sheets, and websites, to find evidence to support their claims. They must provide a link between the evidence and their claims, and write their ideas on paper provided by the teacher. (Wandee's lesson plan, December, 17 2016)

\subsubsection{They Linked More Ethical and Moral Aspects to Their Lessons by Discussion about SSIs}

Initially, all cases admitted that they had not linked ethical and moral aspects to the scientific concepts covered in class. PSTs in this study only addressed ethical and moral issues with respect to coursework, such as examinations. Somsri also emphasized that students should feel empathy toward each other in her classroom, as she reflected: I used extra points to control the classroom. To receive extra points, they have to have good behavior, not talk together when I teach, and help each other to do group activities. In addition, they have to clean their table and chairs, as well as return learning instruments and media back to the provided areas. (The group meeting, October 21, 2016)

While participating in the OM program, they used discussion as the main method for linking ethical and moral aspects to their lessons. Wandee also asked her students to discuss personal differences and empathy for transgender people. Similarly, Somsri asked her students to discuss empathy toward another person. For Ratree, she let her students discuss how ethics and morals influenced their decisions regarding SSIs. As the result of their discussion, they reported that their students seemed to demonstrate more empathy towards others. For example, Somsri, reflected, "At first, I focused on honesty and punctuality in my class. For SSIs-based teaching lesson, my students seemed to think of other people, not just themselves" (The group meeting, February 5, 2017).

\subsubsection{They Provided the Students' an Opportunity to Assess Their Own Learning}

Prior to the OM program, the three cases provided few opportunities for their students to assess their own learning. The teacher was the main person in learning assessment process. They focused on the cognitive domain, rather than psychomotor and affective domains. As Wandee stated: I emphasized assessing students' knowledge from worksheets, tests, or even discussion in classroom. For skills, I only assessed group work skills based on how well they worked together. In the affective domain, students were assessed on whether they handed in their assignments on time or not. (The group meeting, October 21, 2016)

With a better understanding of learning assessment through SSIs-based teaching, all of them began to assess student learning based on higher-order practices. In addition, they provided the opportunity for students to assess their own learning with various methods. They asked students to reflect on their own reasoning during discussion as a means of formative assessment. As result of student self-assessment, the three case studies reported that the learning process was enhanced for most students when they were able to identify their weak and strong points. After teaching, their students seemed to get benefit from their changes of learning assessment. As Ratree stated: $I$ found that my students dared to share more ideas in classroom. Students who used to rarely share ideas, now, provided their answers with reasons. Before, they would copy the outstanding students' ideas or information from internet without doing any critical thinking. (Interview, December 28, 2016)

\subsection{The Satisfactions of the OM program for Promoting PSTs' Understanding and Practices of SSIs-Based} Teaching

\subsubsection{The OM Program Provided Valuable Feedback through Meaningful Assessment Strategies}

Before participation, Wandee and Ratree were accustomed to pre-post multiple-choice tests with automated feedback on whether the answer was correct or incorrect. Somsri had participated in some professional development programs, and these programs assessed the effectiveness by asking participants to complete a satisfaction survey, as she said, "I used to participate in workshops about science teaching, and I was only asked to complete the satisfaction form. There were no assessments or follow up to reflect whether I increased my understanding about content covered in the workshop" (The group meeting, October 21, 2016).

However, the OM program in this study has pre- and post-tests, as well as formative assessments, for each lesson 
that reflect what the participants should have learned. Through these assessments, the case studies were able to identify their weak points. Consequently, they pointed the appreciation of assessment in the OM program after they finished the program as Ratree reflected: The assessments in this program not only told me my score, but what I had to work on. For example, I said that the learning assessment for SSIs-based teaching is provided by the teacher. I got feedback that students should also have the opportunity to assess their own learning. In addition, I was not aware about rubric scoring until I received feedback on my answer. (The group meeting, February 5, 2017)

\subsubsection{OM Programs Provide a Flexible and Convenient Way to Provide Professional Development}

Before participating in the OM program, all cases mentioned their prior experiences with PD programs. They mentioned time constraints as a major barrier. Ratree pointed out the difficulty of transportation and her limited budget as reasons for not participating in PD programs. All of them agreed to participate in the OM program if it was convenient and with minimal expense, as Ratree reflected, "Honestly, I do not want to participate in a workshop because it is inconvenient to find transportation. If I take a taxi, I have to pay a lot. Furthermore, every time I join a workshop, I spend too much money" (The group meeting, October 21, 2016).

With the OM program, all three cases were able to manage their time for learning. Wandee learned and reviewed lessons whenever she had free time in her schedule. In addition, whenever she encountered problems, she was able to access the program to discuss with her mentor or post a question on the discussion board. As she stated: When I wonder about something regarding SSIs-based teaching, I could ask experts from Google hang out. For example, I was worried about whether or not my students understood all concepts with fewer lectures in class. I got the idea that I have to reduce my role little by little and facilitate students to discuss the expected concepts that they are learning (The group meeting, February 5, 2017)

Similarly, Somsri revealed that she accessed the OM program at night, or on the bus to school: I can participate in the OM program anywhere there is an internet signal, even in the bus on the way to and from school. I can also review what I learned anytime. When I have a question about SSIs-based teaching, I can open the OM program to learn and post on the discussion board, without spending time on transportation to meet with an expert for consultation. Moreover, I can learn from other posts as well. (Interview, December 28, 2016)

Ratree also commented on the convenience of the OM program: I benefitted from participating in the OM program, which I did during my free time at my dormitory. Since it was easy to learn anytime, this program is appropriate for those who want to develop their skills, but do not have much time. You can pause and revisit the lesson, as needed. In addition, there are no expenses for transportation. (The group meeting, February 5, 2017)

\subsubsection{The Informal Sharing of Ideas Enhances the Learning Process with OM Programs}

With minimal experience with SSIs-based teaching, the case studies lacked confidence in using this teaching approach prior to the OM program. Therefore, they needed to consult with an expert in order to implement this approach inside the classroom. Somsri and Ratree pointed out that other professional development programs that they had participated in were short and did not provide enough time for discussion with experts. For example, Somsri commented that "The program that I previously participated in was short, so I did not have much of a chance to ask questions" (Interview, December 28, 2016).

As the OM program progressed, Wandee had a better understanding of social constructivism from discussion with friends and experts. As she stated during a group meeting:

I learned more about SSIs-based teaching from discussion on the discussion board in the OM program. It reminded me about social constructivism, which occurred from chatting with other people who had more knowledge and skills. Importantly, I was more aware of student learning based on their interests or curiosity, rather than by lecture. (The group meeting, February 5, 2017)

Somsri benefitted from feedback on her teaching practices, as well as suggestions in the discussion board, as stated: I like this style of learning because I know what I do not know. I dared to ask questions because the experts or my friends did not see my face, so I was not too shy to ask. In addition, I got encouragement from discussion with experts. I am not learning alone, and there is an expert to exchange ideas and give me some feedback. (Interview, February 10, 2017)

Similarly, Ratree used the discussion board to exchange ideas with experts and friends. This helped to improve her knowledge about SSIs-based teaching, as stated: I learned from my friends' comments on the discussion board. When they posted their questions, I reflected back to my understanding on whether it is right or wrong. In addition, discussions with experts made me feel confident about SSIs-based teaching. It is similar to a real classroom setting. For example, if my students could not share ideas in the classroom, how would I promote the 
sharing their ideas? From discussions, I learned that students at this age always think about themselves first, so I should ask them individually to write their ideas down on a small piece of paper before using probing questions to share their opinion in the classroom. (The group meeting, February 5, 2017)

\section{Conclusion and Discussions}

The findings from the three cases revealed that, before participating in the OM program, they were unclear on the definition of SSIs. Consistent with the literature, these findings demonstrate that that PSTs generally have limited SSI knowledge and as result, focus on issues that they are more familiar with (Forbes \& Davis, 2008). While participating in the OM program, they gradually developed a better understanding on the definition of SSIs, as reflected by their post-test responses. They were able to identify which of the presented issues were SSIs, and their rationale was correct. For the importance of SSIs-based teaching, they previously focused on the transmission of content knowledge to their students. As Pillay (2002) noted, the Thai education system places a strong emphasis on technical knowledge, rather than the essential skills for becoming an informed citizen. As the OM program progressed, they could identify important aspects of SSIs-based teaching. They mentioned ways that it can enhance scientific literacy. Similarly, Presley et al. (2013) pointed out that SSIs are open-ended social problems with substantive connections to science. Teachers can use them to enhance scientific literacy.

Prior to the OM program, the three cases did not know the main characteristics of SSIs-base teaching, especially the link to ethics and morals. Similarly, Levison and Turner (2001) found that many teachers felt that they lack pedagogical knowledge, understanding of ethical frameworks for ethical thinking related to SSIs, and classroom resources. Through the OM program, they understood the characteristics of SSIs, ways to use SSIs to drive a lesson, the role of teacher and the role of students. These understandings had a direct impact on their teaching practices. As Nuangchalerm (2009) indicated, if PSTs have a good foundation in SSIs-based teaching, they will consider this teaching approach in their teaching practices.

In addition, all case studies initially accepted that they did not know much about the teaching models for SSIs-based teaching. However, after the fourth lesson of the OM program, they were able to identify various teaching models for SSIs-based teaching, such as decision-making models (Ratcliffe, 1997), bioethical model (Van Rooy, 2000), or model for discursive argument (Levinson, 2003). Furthermore, they expanded on their understanding of learning assessment to include assessment of students' higher order practices, such as scientific claims and arguments. As the OM program progressed, their understanding of learning assessment evolved with respect to assessing students' higher-order practices. This kind of learning assessment is appropriate for SSIs-based teaching because SSIs deal with conflicting opinions, so students are required to engage in higher-order practices, such as argumentation, reasoning, and decision making (Presley et al., 2013).

For teaching practice, their practices initially did not reflect the ability to use SSIs as a useful context for students to learn about specific science content knowledge, or make appropriate connections of the content to other areas of science or to other disciplines (Sadler, Barab, \& Scott, 2007). In addition, all cases accepted that they had not linked ethical and moral aspects to the scientific concepts covered in class. This finding was similar to Levinson (2001) who found that most teachers also see their task as teaching the facts and not discussing the social, moral and ethical implications of science and technology in the lessons. However, during participation in the OM program, they gradually developed their practices to incorporate social dimensions. To support this finding, Barrett and Nieswandt (2010) found that successful SSIs-based teaching depends on the teachers' awareness of social considerations associated with the issue, such as potential political, economic, and ethical challenges. In addition, they use media from the internet to link their lesson with social dimensions. As Evagorou (2011) pointed out, technology can be used in a variety of ways to enhance SSIs-based teaching and has the potential to be a powerful tool in providing access to relevant social issues.

For learning assessment, the three cases provided few opportunities for their students to assess their own learning prior to the OM program. Summative assessment was their focus in learning assessment. Sadler and Donnelly (2006) indicated that teachers might face difficulties in SSI-based planning or teaching if they regard the lesson content or science curriculum objectives as the focus of student evaluation. As the result of the OM program, they provided the opportunity for their students to assess their own learning with various methods. Moreover, they asked students to reflect on their own reasoning during discussion as a means of formative assessment. These practices are supported by Tal and Kedmi (2006), who suggest that SSI teachers implement frequent formative assessments in order to promote the learning process.

In addition, they pointed out their appreciation of the characteristics of the OM program. They pointed that the OM program in this study has pre- and post-tests, as well as formative assessments, for each lesson that reflect what the participants should have learned. Through these assessments, the case studies were able to identify their 
weak points. Consequently, they pointed the appreciation of assessment in the OM program after they finished the program. This finding also supported Conrad (2002) who found that reflecting carefully and with empathy during interaction serves to support student learning. In addition, they found that OM programs provide a flexible and convenient way to provide professional development. Similarly, Hunt (2005) suggested that an OM program should be easy for participants to join and actively participate. It should be flexible and convenient enough that it fits into the day-to-day work schedule. Moreover, they appreciated the informal sharing of ideas enhances the learning process with OM program. These findings are similar to Bell (1998) who indicated that teachers who participate in a PD program are more likely to construct knowledge when human social interaction is an integral part of learning activity. Therefore, the OM program needs to be capable of building a community within which the participants can communicate in confidence and share information (Hunt, 2005).

\section{Recommendations}

This study found that the OM program was effective in enhancing PSTs' understanding and practices of SSIs-based teaching. However, this research study involved the evaluation of a newly developed OM program for SSIs-based teaching based on a small, target group of PSTs. In the next study, the researcher should extend the OM program to a wider audience of teachers, particularly those living in remote areas, to determine whether the observed findings are generalizable. Since this OM program was in its infancy, the researcher was the main person to provide feedback to participants during the evaluation. In order for the OM program to be more effective and have a greater impact, it is important to find more experts in SSIs-based teaching to assist with mentoring. Lastly, this study focused on the impact of the OM on program on PSTs' understandings and practices of SSIs-based teaching, so there is limited information on the impact of this program on student learning. When PSTs' used SSIs-based methods, we did find that their students had some difficulties with this new style of teaching. Thus, future research should focus on student learning when implementing this teaching approach.

\section{References}

Bang, E., \& Luft, J. A. (2014). Exploring the written dialogues of two first-year secondary science teachers in an online mentoring program. Journal of Science Teacher Education, 25, 25-51. https://doi.org/10.1007/s10972-013-9362-z.

Barrett, S. E., \& Nieswandt, M. (2010). Teaching about ethics through socioscientific issues in physics and chemistry: Teacher candidates' beliefs. Journal of Research in Science Teaching, 47, 380-401. https://doi.org/10.1002/tea.20343.

Beck, C., \& Kosnik, C. (2002). Components of a good practicum placement: Student teacher perceptions. Teacher Education Quarterly, 29(2), 81-98.

Bell, B. (1998). Teacher development in science education. In B. J. Fraser, \& K. G. Tobin (Eds.), International Handbook of Science Education (pp. 681-693). Great Britain: Kluwer Academic Publishers.

Cohen, L., Manion, L., \& Morrison, K. (2000). Research Methods in Education (5th ed.). New York: Routledge Falmer.

Conrad, D. (2002). Inhibition, integrity, and etiquette among online learners: The art of niceness. Distance Education, 23(2), 197-212. https://doi.org/10.1080/0158791022000009204

Elbaz, F. L. (1981). The teacher's practical knowledge: Report of a case study. Curriculum Inquiry, 11, 43-71. https://doi.org/10.1080/03626784.1981.11075237

Ensher, E. A., Heun, C., \& Blanchard, A. (2003). Online mentoring and computer-mediated communication: New directions in research. Journal of Vocational Behavior, 63, 264-288. https://doi.org/10.1016/S0001-8791(03)00044-7

Evagorou, M. (2011). Discussing a socioscientific issue in a primary school classroom: The case of using a technology supported environment in formal and nonformal settings. In T. D. Sadler (Ed.), Socio-scientifi c issues in science classrooms: Teaching, learning and research (pp. 133-159). New York: Springer.

Feiman-Nemser, S. (2012). Beyond solo teaching. Educational Leadership, 69(8), 10-16.

Forbes, C. T., \& Davis, E. A. (2008). Exploring preservice elementary teachers' critique and adaptation of science curriculum materials in respect to socioscientific issues. Science and Education, 17(1), 829-854. https://doi.org/10.1007/s11191-007-9080-z

Gewin, V. (2005). Learning to mentor. Nature, 436, 436-437. https://doi.org/10.1063/1.5019530 
Hunt, K. (2005). E-mentoring: Solving the issue of mentoring across distances. Development and Learning in Organizations, 19(5), 7-10. https://doi.org/10.1108/14777280510616221

Klosterman, M. L., Sadler, T. D., \& Brown, J. (2012). Science teachers' use of mass media to address socio-scientific and sustainability issues. Research in Science Education, 42, 51-74. https://doi.org/10.1007/s11165-011-9256-z

Kolstø, S. D. (2001). Scientific literacy for citizenship: Tools for dealing with the science dimension of controversial socioscientific issues. Science Education, 85(3), 291-310. https://doi.org/10.1002/sce.1011

Lee, H., Abd-El-Khalick, F., \& Choi, K. (2006). Korean science teachers' perceptions of the introduction of socioscientific issues into the science curriculum. Canadian Journal of Science, Mathematics and Technology Education, 6(2), 97-117. https://doi.org/10.1080/14926150609556691

Levinson, R. (2003). Teaching ethics to young people. In R. Levinson \& M. Reiss (Eds.), Key issues in bioethics. London: Routledge Falmer.

Levinson, R., \& Turner, S. (2001). Valuable lessons: Engaging with the social context of science in schools. London: The Wellcome Trust.

Lichtenstein, G., McLaughlin, M. W., \& Knudsen, J. (1992). Teacher empowerment and professional knowledge. In A. Lieberman (Ed.), The changing contexts of teaching (pp. 37-58). Chicago: University of Chicago Press.

Lincoln, Y. S., \& Guba,E. G. (1985). Naturalistic inquiry. CA: Sage.

Michigan Virtual University. (2014). Mentor Fundamentals: A Guide for Mentoring Online Learners Version 1 August 2014. Retrieved from https://micourses.org/resources/pdf/toolkit/mentor_guide_14.pdf

Miller, H., \& Griffiths, M. (2005). E-mentoring. In D. L. DuBois, \& M. J. Karcher (Eds.), Handbook of youth mentoring (pp. 300-313). Thousand Oaks, London \& New Delhi: Sage.

Miller, K. (1999). Mentoring via Mouse. Retrieved from http://www.startribune.com

Northfied, J. (1998). Teacher educators and the practice of science teacher education. In B. J. Fraser \& K. G. Tobin (Eds.). International Handbook of Science Education. The Netherlands: Kluwer Academic Publisher.

Nuangchalerm, P. (2009). Development of socioscientific issues-based teaching for preservice science teachers. Journal of Social Sciences, 5(3), 239-243. https://doi.org/10.3844/jssp.2009.239.243

Nuangchalerm, P., \&Kwuanthong, B. (2010). Teaching "Global Warming” through Socioscientific issues-based instruction. Asian Social Science, 6(8), 42-47. https://doi.org/10.5539/ass.v6n8p42

Patton, M. Q. (2002). Qualitative Evaluation and Research Methods (3rd ed.). CA: Sage.

Pena, C. M., \& Almaguer, I. (2007). Asking the right questions: Online mentoring of students teachers. International Journal of Instructional Media, 34(1), 105-113.

Perren. L. (2003).The role of e-mentoring in entrepreneurial education and support: a meta-review of academic literature. Education \& Training, 8(9), 517-525. https://doi.org/ 10.1108/00400910310508900

Perry, C. M., \& Power, B. M. (2004). Finding the truths in teacher preparation field experiences. Teacher Education Quarterly, 31(2), 125-136.

Pillay, H. (2002). Teacher Development for Quality Learning: The Thailand Education Reform Project. Brisbane: Queensland University of Technology.

Presley, M. L., Sickel,A. J., Muslu, N., Johnson , D. M., Witzig, S. B., Izci, K., \& Sadler, T. D. (2013). A framework for socio-scientific issues-based education. Science Educator, 22(1), 26-32.

Ratcliffe, M. (1997). Pupil decision-making about socioscientific issues within the science curriculum. International Journal of Science Education, 19(2), 167-182. https://doi.org/10.1080/0950069970190203.

Roberts, D. (2007). Scientific literacy/science literacy. In S. Abell, \& Lederman (Eds.), Handbook of Research on Science Education (pp. 729-780). Mahwah, NJ: Lawrence.

Sadler, T. D., \& Donnelly, L. A. (2006). Socioscientific argumentation: The effects of content knowledge and morality. International Journal of Science Education, 28(12), 1463-1488. https://doi.org/10.1080/09500690600708717

Sadler, T. D. (2004). Informal reasoning regarding issues: A critical review of research. Journal of Research in Science Teaching, 41(5), 513-536. https://doi.org/10.1002/tea.20009. 
Sadler, T. D., Barab, S. A., \& Scott, B. (2007). What do students gain by engaging in socioscientific inquiry?. Research in Science Education, 37(4), 371-391. https://doi.org/10.1007/s11165-006-9030-9

Saunders, K. J., \& Rennie, L. (2011). A pedagogical model for ethical inquiry into socioscientific issues in science. Research in Science Education, 43(20), 1-22. https://doi.org/10.1007/s11165-011-9248-z

Shpigelman, C. N., Weiss, P. L., \& Reiter, S. (2009). E-Mentoring for all. Computers in Human Behavior, 25 , 919-928. https://doi.org/10.1016/j.chb.2009.03.007

Tal, T., \& Kedmi, Y. (2006). Teaching socioscientific issues: classroom culture and students' performances. Cultural Studies of Science Education, 1, 615-644. https://doi.org/10.1007/s11422-006-9026-9

van Driel, J. H., de Jong, O., \& Verloop, N. (2002). The development of preservice chemistry teachers' pedagogical content knowledge. Science Education, 86, 572-590. https://doi.org/10.1002/sce.10010

Van Rooy, W. (2000). Controversial issues within biology: enriching biology teaching. Australian Science Teachers' Journal, 46(1), 20-27.

Wah, L. (2000). Workplace of the future. Management Review, 89(1), 1-2.

Wongsri, P., \& Nuangchalerm, P. (2010). Learning outcomes between socioscientific issues-based learning and conventional learning activities. Journal of Social Sciences, 6(2), 240-243. https://doi.org/10.3844/jssp.2010.240.243.

Zembal-Saul, C., Blumenfeld, P., \& Krajcik, J. (2000). Influence of guided cycles of planning, teaching, and reflection of prospective elementary teachers' science content representations. Journal of Research in Science Teaching, 37(4), 318-339. https://doi.org/10.1002/(SICI)1098-2736(200004)37:4<318::AID-TEA $3>3.0 . \mathrm{CO} ; 2-\mathrm{W}$.

\section{Copyrights}

Copyright for this article is retained by the author(s), with first publication rights granted to the journal.

This is an open-access article distributed under the terms and conditions of the Creative Commons Attribution license (http://creativecommons.org/licenses/by/4.0/). 